\title{
Impact of FORMOSAT-3/COSMIC GPS radio occultation and dropwindsonde data on regional model predictions during the 2007 Mei-yu season
}

\author{
Fang-Ching Chien · Ying-Hwa Kuo
}

Received: 2 March 2009/Accepted: 2 September 2009/Published online: 22 September 2009

(C) The Author(s) 2009. This article is published with open access at Springerlink.com

\begin{abstract}
A study of the impact of FORMOSAT-3/ COSMIC GPS radio occultation (RO) and dropwindsonde data on regional model simulations for a 11-day period during the 2007 Mei-yu season is presented. The Weather Research and Forecasting (WRF) model and its threedimensional variation component, WRF-Var, are used for regional model predictions of heavy rainfall events in Taiwan. Without the use of GPS RO and dropwindsonde data, pressure and relative humidity are, in general, underestimated by the model; temperature predictions have a warm bias at the low level and a cold bias at the high level; and the east-west and north-south component winds have positive and negative biases, respectively. Incorporating GPS RO data tends to improve the prediction for longer integration. The assimilation of dropwindsonde data improves the forecast at the earlier time and at higher levels, and the improvement decreases over time. The reason the dropwindsonde data produce a positive impact earlier and the GPS RO data later is that there are few GPS RO observations in the fine domain. The large-scale simulation is first improved using the GPS RO observations, and the resulting changes can have a positive impact on the mesoscale at the later time. The dropwindsonde observations were taken inside the fine domain such that their impact can be detected early in the simulation. With both
\end{abstract}

F.-C. Chien ( $\square)$

Department of Earth Sciences, National Taiwan Normal

University, No. 88, Section 4, Ting-Chou Road,

Taipei 116, Taiwan

e-mail: jfj@ntnu.edu.tw

Y.-H. Kuo

Mesoscale and Microscale Meteorology (MMM) Division, National Center for Atmospheric Research, Boulder, CO 80307-3000, USA types of observation included, the prediction shows even greater improvement. At the earlier forecast time, there is nearly no impact from GPS and dropwindsonde data on rainfall forecasts. However, at the later integration time, the GPS data start to significantly improve the rainfall forecast. The dropwindsonde data also provide a positive impact on rainfall forecasts, but it is not as significant as that of the GPS data.

Keywords FORMOSAT-3 - COSMIC - GPS ·

Radio occultation · Dropwindsonde · Mei-yu · WRF . Data assimilation

\section{Introduction}

The six Formosa Satellite Mission 3/Constellation Observing System for Meteorology, Ionosphere, and Climate (FORMOSAT-3/COSMIC) microsatellites carry global positioning system (GPS) radio occultation (RO) receivers to measure the phase and amplitude of GPS signals (Anthes et al. 2000, 2008). Using these data, the vertical profiles of bending angle and atmospheric refractivity are obtained (Kuo et al. 2004), and atmospheric soundings can be retrieved (Kursinski et al. 1997). The present orbital configuration is providing global coverage of approximately 1,400-2,300 soundings per day.

The impact of GPS RO observations on numerical weather prediction has been intensively studied over the last decade. For example, Liu et al. (2001) studied the impact of global positioning system/meteorology (GPS/MET) bending-angle profiles; Zou et al. (2004) examined the impact of RO observations from the Challenging Minisatellite Payload (CHAMP) mission; Cucurull et al. (2006, 2008) assessed the impact of CHAMP and COSMIC GPS RO data; 
and Kuo et al. (2008) evaluated the impact of COSMIC GPS RO soundings. These studies show the positive and potential impact of assimilating GPS RO observations into numerical models. Several operational centers have also demonstrated the positive impact of COSMIC data on numerical weather prediction (NWP) products. For example, the European Center for Medium-Range Weather Forecasts (ECMWF) NWP system obtains a significant reduction of stratospheric temperature forecast errors, especially in the southern hemisphere, by assimilating COSMIC data (Healy and Thepaut 2006). The National Oceanic and Atmospheric Administration/National Weather Service (NOAA/NWS) has seen a similarly significant improvement in the prediction of 500-hPa pressure surface height, called herein geopotential height, with COSMIC data assimilation (Cucurull et al. 2007, 2008).

During a Mei-yu (plum rain) season, which usually occurs from mid-May to mid-June, quasi-stationary fronts frequently form over southeastern China and move to the Taiwan area, resulting in extended periods of precipitation. The Southwest Monsoon Experiment/Terrain-influenced
Monsoon Rainfall Experiment (SoWMEX/TiMREX) is an international collaborative field experiment that collected special observations over the western plains and mountain slope region of southern Taiwan during the 2008 Mei-yu season. The program attempts to examine physical processes leading to the development of heavy orographic precipitation (http://sowmex.cwb.gov.tw). A pilot experiment of this project was conducted during the 2007 Mei-yu season. During a heavy rain event that occurred in central and southern Taiwan from 5 to 10 June 2007 (Fig. 1), dropwindsonde observations were undertaken over the Taiwan Strait and the northern South China Sea. Satellite and radar observations show a deep and widespread lowlevel, moisture-laden southwesterly flow during this time period (see Fig. 1b, c, for example). As documented in previous studies (Lin et al. 2001; Chen et al. 2006; Chien et al. 2006, 2008), this upstream flow is often associated with organized mesoscale convective systems (MCS) forming over the strait, propagating eastward, and producing heavy rain over the sloping mountainous area. In this study, we perform data assimilation experiments to

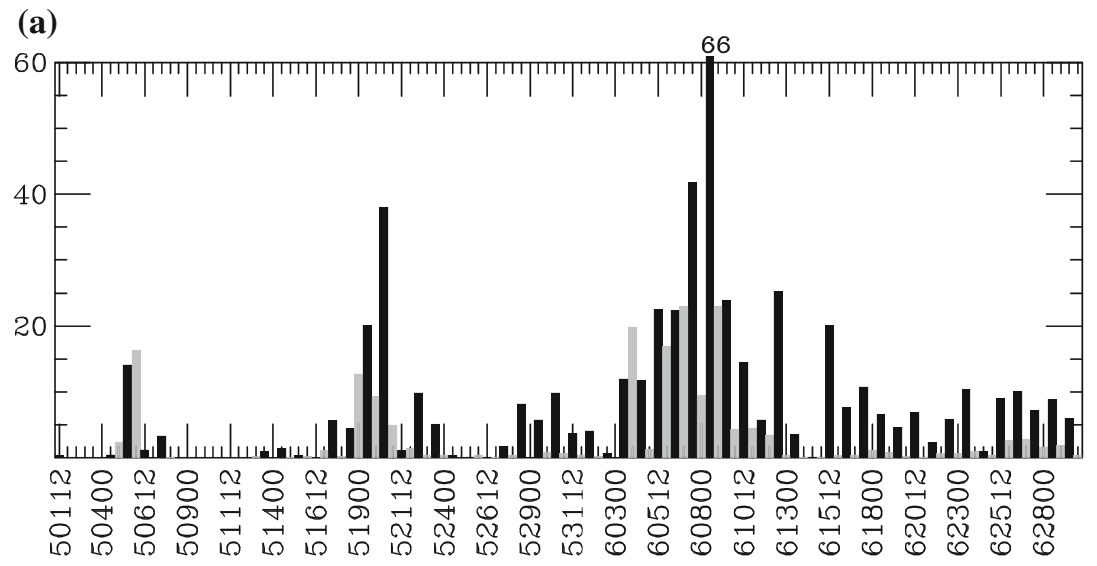

(b)

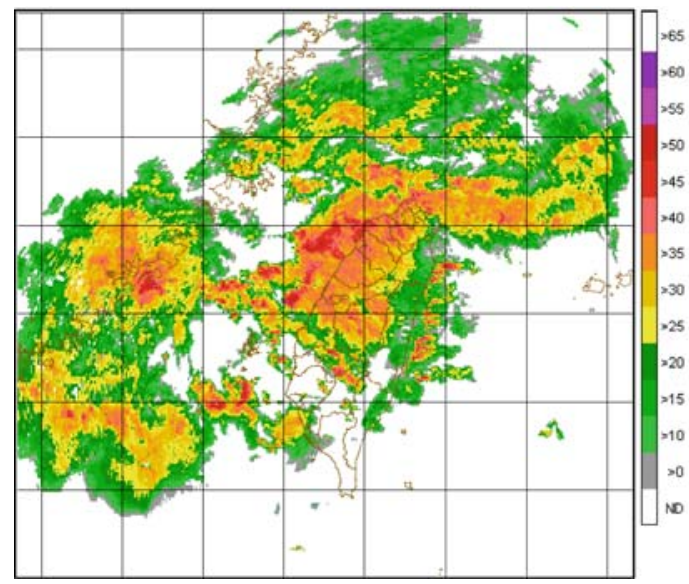

(c)

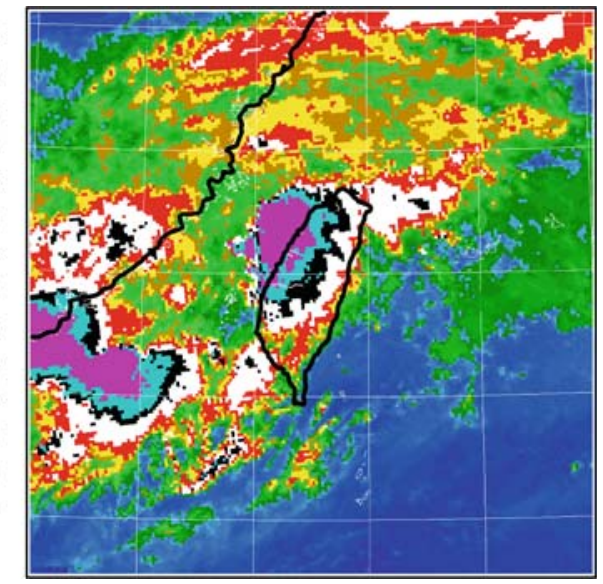

Fig. 1 Observations from gauges, radar, and satellite. a Twelve-hour accumulated rainfall in Taiwan during May and June 2007. The rainfall amount $(\mathrm{mm})$ shown here is an average of all the 390 rain gauge stations over Taiwan. b, c Radar reflectivity and an infrared image, respectively, at 0000 UTC 8 June 2007 
assess the ability of a mesoscale model to predict these precipitating systems.

In the last decade, dropwindsonde observations have been used intensively for hurricane studies. Two major programs that collected such soundings took place over the Atlantic and the western North Pacific Oceans, the former led by the National Oceanographic and Atmospheric Administration's (NOAA) Hurricane Research Division (Aberson and Franklin 1999), and the latter by the Dropwindsonde Observations for Typhoon Surveillance near the Taiwan Region team (DOTSTAR; Wu et al. 2005). After assimilating dropwindsonde data, the National Centers for Environmental Prediction (NCEP) reported an improvement of up to $30 \%$ for $12-60$-h track forecasts in its operational numerical model (Burpee et al. 1996). Aberson and Franklin (1999) showed that dropwindsonde observations brought significant improvement to the Geophysical Fluid Dynamics Laboratory (GFDL) track and intensity forecasts. Wu et al. (2007) evaluated the impact of dropwindsonde data on tropical cyclone track forecasts in five different models, including the NCEP Global Forecast System (GFS), the Navy Operational Global Atmospheric Prediction System (NOGAPS), the Japanese Meteorological Agency (JMA) Global Spectral Model (GSM), the Weather Research and Forecasting (WRF) model, and the GFDL hurricane model. They concluded that all models, but the GFDL model, produce remarkably better track forecasts after the assimilation of dropwindsonde data.

In this paper, we consider dropwindsonde observations during the pilot field observation of the SoWMEX together with the FORMOSAT-3/COSMIC GPS RO data to examine their impact on regional weather predictions during a 11-day period from 5 to 15 June 2007. The experiment designs are introduced in Sect. "Experiment designs". The verification results for the different experiments are analyzed in Sects. "Verification of HTRUV" and "Verification of rain". A summary is given in Sect. "Summary and conclusions".

\section{Experiment designs}

The WRF model and its 3D-VAR component, WRF-Var, are used for the regional forecasting of heavy rainfall events in Taiwan during the 2007 Mei-yu season. The model includes two domains with $45-$ and $15-\mathrm{km}$ horizontal spacing (see Fig. 2a) and 31 levels in the vertical. We use the WRF Single-Moment 5-class microphysics scheme, the Kain-Fritsch cumulus parameterization scheme, and the Yonsei University (YSU) PBL scheme (Skamarock et al. 2005) in model simulations. Four experiments are conducted for this study (Table 1): the
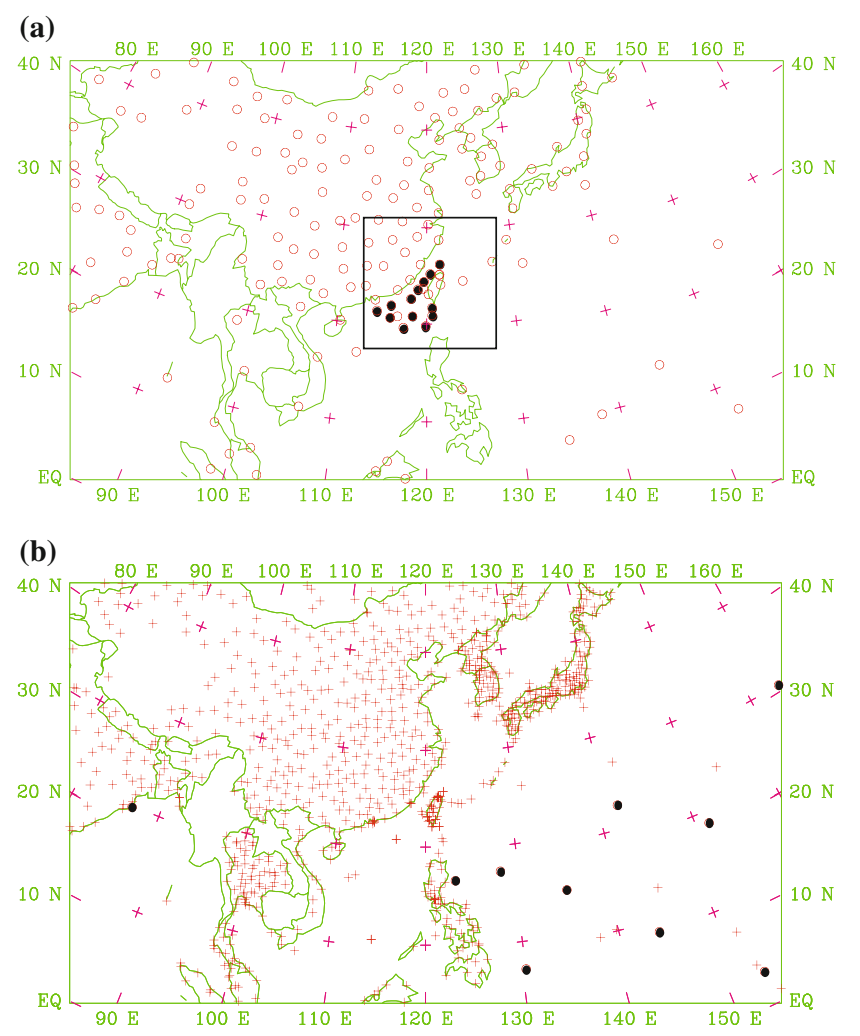

Fig. 2 The locations of observation data within domain 1 from a traditional soundings plus dropwindsonde and b synoptic surface stations plus GPS RO at 0000 UTC 6 June 2007. There were 155 soundings (circles), 13 dropwindsondes (black dots), 877 surface data points (crosses), and 10 GPS RO observations (black dots). The inset in a denotes the location of domain 2

control experiment $(\mathrm{CON})$ uses the conventional observation data in the WRF-Var data assimilation; the GRO and DWS experiments are the same as the CON experiment, except that the data from FORMOSAT-3/COSMIC GPS RO and dropwindsonde observations, respectively, are added to the data assimilation; and the ALL experiment includes all the aforementioned data in the assimilation. Table 2 shows the amount of available data that are located inside domain 1 at a 12-h interval during this 11-day period. A 6-h time window (between -3 and $+3 \mathrm{~h}$ ) was used for the collection of the GPS RO data. Figure 2 presents an example of the locations of observations from each observing platform at 0000 UTC 6 June 2007. While the GPS RO data were distributed over a widespread area, the dropwindsonde data were mostly collected over the ocean to the southwest of Taiwan. The GPS RO data, obtained from the Taiwan Analysis Center for COSMIC (TACC) in Taiwan (http://tacc.cwb.gov.tw), contain vertical profiles of refractivity at $100-\mathrm{m}$ vertical resolution. During the assimilation process, the model refractivity was calculated and then converted to the observation space with horizontal and vertical interpolation. The innovations of refractivity were computed in the observation space. With these 
Table 1 The experiment designs

\begin{tabular}{lll}
\hline Experiments & $\begin{array}{l}\text { Data assimilated } \\
\text { (common) }\end{array}$ & $\begin{array}{l}\text { Data assimilated } \\
\text { (special) }\end{array}$ \\
\hline CON & SYNOP, SOUND & N/A \\
GRO & SYNOP, SOUND & GPS RO \\
DWS & SYNOP, SOUND & DROP \\
ALL & SYNOP, SOUND & GPS RO, DROP \\
\hline
\end{tabular}

SYNOP observations from surface stations, SOUND observations from sounding stations, GPS RO radio occultation observations from GPS satellite, DROP sounding observations from dropwindsonde

innovations, the increments of the model analysis variables were obtained through a three-dimensional variational data assimilation approach.

Each of the four experiments contains 22 runs of 72-h WRF simulations. These runs were initialized twice daily from 0000 UTC 5 June to 1200 UTC 15 June 2007. The initial data (first guess) for the first run at 0000 UTC 5 June 2007 were obtained from the NCEP GFS, while those for the other 21 runs were from the 12-h forecast of their previous WRF runs (i.e., 12-h update cycling). Because the GPS data were provided continuously in time, the 12-h cycling may not be good enough to take advantage of all available observations. Thus, another GRO experiment, but with 6-h cycling, was performed for comparison. It is found that the forecasts of the 6-h cycling GRO overall are slightly worse than those of the 12 -h cycling GRO at the earlier forecast time, but they become slightly better at the longer integration time (not shown).

\section{Verification of HTRUV}

The verification was performed by comparing the geopotential height $(H)$, temperature $(T)$, relative humidity $(\mathrm{RH})$, and east-west and north-south wind components ( $U$ and $V$ ) with those of the NCEP GFS analyses (with mesoscale data assimilation of traditional surface and upper-air observations). These five meteorological variables together are hereafter referred to as HTRUV. The root-mean square error (RMSE), mean error (ME), and skill score (SS) are calculated by using data from all the grid points in domain 2 for all the 22 runs during the 11-day period. These are defined as follows:

$\mathrm{RMSE}=\sqrt{\frac{\sum_{n=1}^{N}\left(F_{n}-O_{n}\right)^{2}}{N-1}}$

$\mathrm{ME}=\frac{\sum_{n=1}^{N}\left(F_{n}-O_{n}\right)}{N}$

$\mathrm{SS}=-\frac{\mathrm{RMSE}_{\mathrm{GPS}}-\mathrm{RMSE}_{\mathrm{CON}}}{\mathrm{RMSE}_{\mathrm{CON}}} \times 100 \%$

where $F$ and $O$ are the forecast and observation fields, respectively. $N$ is the number of the sample size. Skill score is defined as the percentage of improvement for a particular experiment (e.g., GRO or DWS) over the reference forecasts $(\mathrm{CON})$. The calculation is done on five pressure levels $(1,000,850,700,500$, and $300 \mathrm{hPa})$, but for brevity, only results at 850,500 , and $300 \mathrm{hPa}$ are shown in the figures.

\section{RMSE}

Figure 3 shows the RMSE of HTRUV by comparing the simulation results from each of the four experiments against the reference analyses. The average was calculated by taking account of simulation data over all the grid points in domain 2 from all the 22 runs. The RMSEs of geopotential height (H; Fig. 3a) increase with time, from about 5 to $15 \mathrm{~m}$ at $850 \mathrm{hPa}$, and up to $20 \mathrm{~m}$ at $300 \mathrm{hPa}$. Comparisons show that GRO performs better (with smaller errors) than $\mathrm{CON}$ at $850 \mathrm{hPa}$ after $36 \mathrm{~h}$, and that the RMSE

Table 2 The data sets used in the WRF-Var data assimilation for the 22 runs during the 11-day period from 0000 UTC 5 June to 1200 UTC 15 June 2007

\begin{tabular}{|c|c|c|c|c|c|c|c|c|c|c|c|}
\hline Init time $(\mathrm{dd} / \mathrm{hh})$ & $05 / 00$ & $05 / 12$ & $06 / 00$ & $06 / 12$ & $07 / 00$ & $07 / 12$ & $08 / 00$ & $08 / 12$ & $09 / 00$ & $09 / 12$ & $10 / 00$ \\
\hline SYNOP & 914 & 964 & 877 & 882 & 898 & 973 & 902 & 902 & 917 & 915 & 916 \\
\hline SOUND & 155 & 140 & 155 & 141 & 153 & 140 & 153 & 138 & 151 & 141 & 152 \\
\hline GPS RO & 9 & 17 & 10 & 20 & 5 & 14 & 10 & 28 & 15 & 20 & 11 \\
\hline DROP & 13 & 0 & 13 & 0 & 8 & 0 & 8 & 0 & 13 & 0 & 7 \\
\hline Init time $(\mathrm{dd} / \mathrm{hh})$ & $10 / 12$ & $11 / 00$ & $11 / 12$ & $12 / 00$ & $12 / 12$ & $13 / 00$ & $13 / 12$ & $14 / 00$ & $14 / 12$ & $15 / 00$ & $15 / 12$ \\
\hline SYNOP & 959 & 904 & 908 & 899 & 914 & 898 & 900 & 891 & 900 & 892 & 927 \\
\hline SOUND & 140 & 152 & 132 & 152 & 138 & 155 & 139 & 151 & 136 & 153 & 135 \\
\hline GPS RO & 24 & 9 & 21 & 8 & 18 & 4 & 20 & 17 & 24 & 12 & 22 \\
\hline DROP & 0 & 0 & 0 & 0 & 0 & 0 & 0 & 0 & 0 & 0 & 0 \\
\hline
\end{tabular}


Fig. 3 Root-mean square error (RMSE) for domain 2. Row $a$ is $H(\mathrm{~m})$, row $b$ is $T\left({ }^{\circ} \mathrm{C}\right)$, row $c$ is $\mathrm{RH}(\%)$, row $d$ is $U(\mathrm{~m} / \mathrm{s})$, and row $e$ is $V(\mathrm{~m} / \mathrm{s})$. Columns from left to right represent

verification results at 850,500 , and $300 \mathrm{hPa}$. The abscissa denotes the time elapsed in the simulation (h). Color bars in red, green, blue, and magenta represent RMSEs for the CON, GRO, DWS, and ALL experiments, respectively

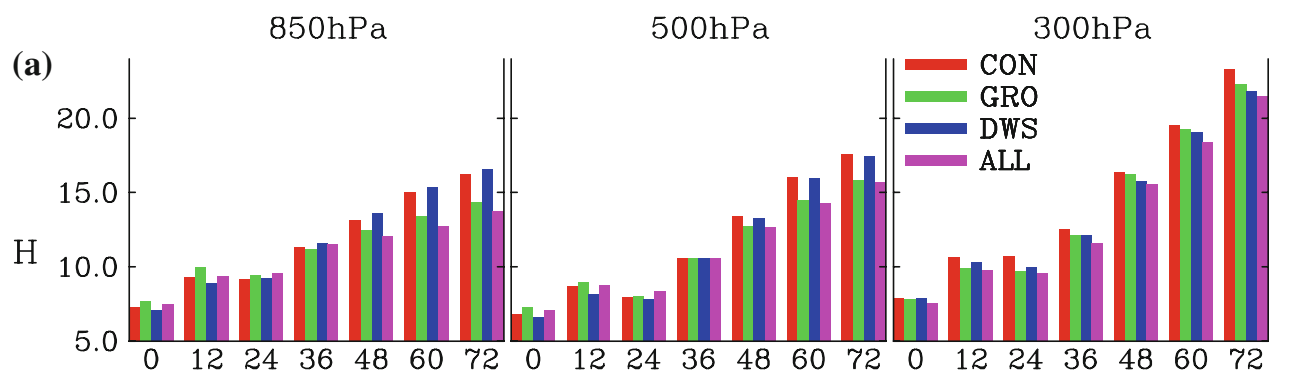

(b)
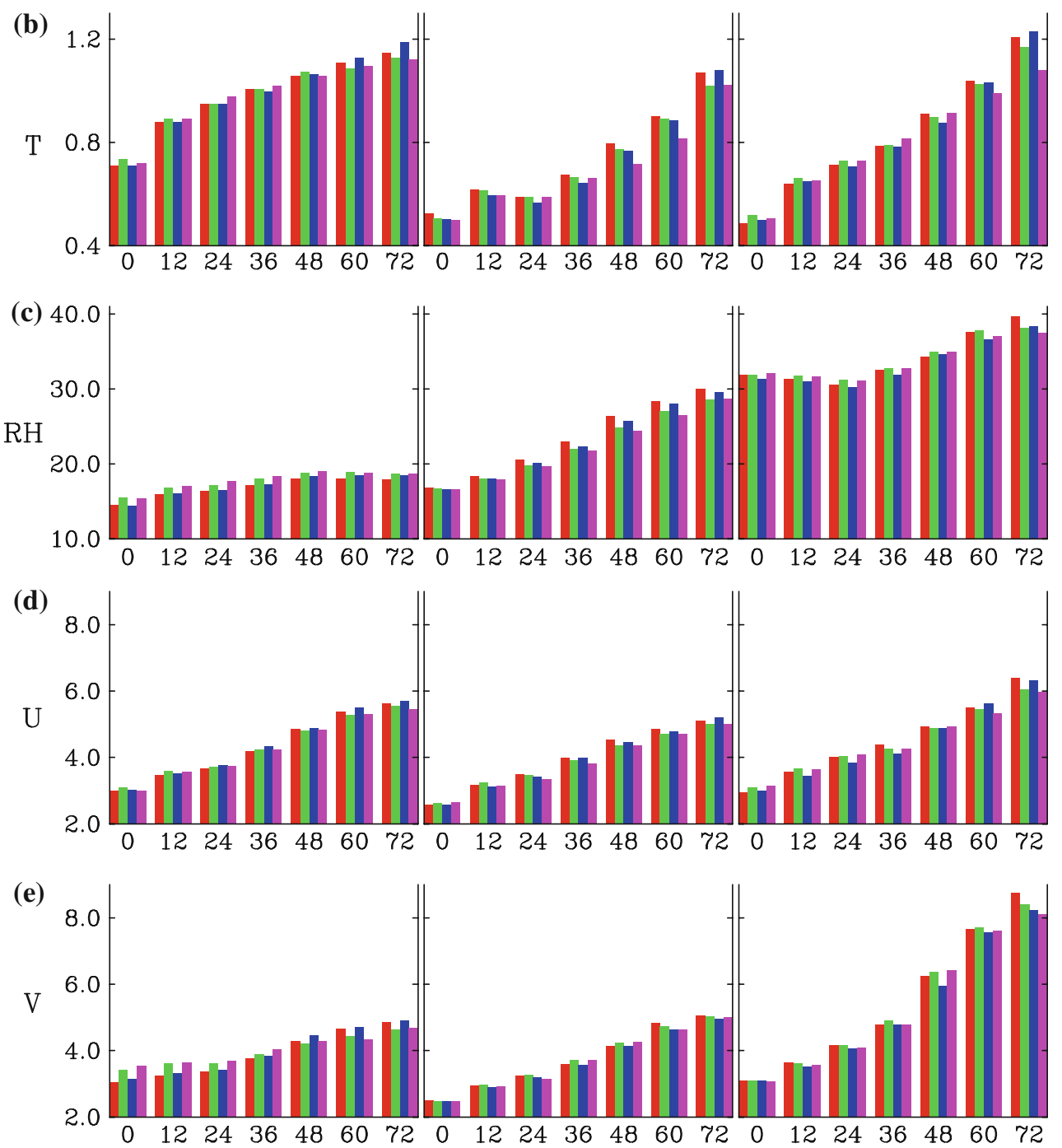

differences between them increase over time. A similar trend is observed at higher levels (500 and $300 \mathrm{hPa}$ ). The RMSEs of DWS at $850 \mathrm{hPa}$ are smaller than those of CON at 12 and $24 \mathrm{~h}$, but they become larger after $24 \mathrm{~h}$. At 500 and $300 \mathrm{hPa}$, most of the RMSEs of DWS are slightly lower than those of CON. Compared with GRO, DWS tends to have smaller RMSEs at the earlier time, but they become larger at the later time. With both the GPS RO and dropwindsonde data assimilated, ALL produces the smallest RMSEs, especially at the longer integration time.
The RMSEs of temperature (T; Fig. 3b) are about $0.7-$ $1.1^{\circ} \mathrm{C}$ at $850 \mathrm{hPa}$ and become smaller at 500 and $300 \mathrm{hPa}$. At 850 and $300 \mathrm{hPa}$, GRO has smaller RMSEs than CON only at the longer integration time (after $\sim 48 \mathrm{~h}$ ). However, GRO produces smaller RMSEs at $500 \mathrm{hPa}$ than CON at all times. DWS also has lower-temperature RMSEs than CON at $500 \mathrm{hPa}$, but produces slightly larger RMSEs most of the time at the other two levels. ALL shows the lowest-temperature RMSEs among all experiments after $48 \mathrm{~h}$. 
For relative humidity (RH; Fig. 3c), the RMSEs are about $15 \%$ at $850 \mathrm{hPa}$, and increase to about $30 \%$ at $300 \mathrm{hPa}$ for all experiments. The RMSEs of GRO are all larger than those of $\mathrm{CON}$ at $850 \mathrm{hPa}$. At $500 \mathrm{hPa}$, however, GRO has smaller RMSEs than CON at all times. At $300 \mathrm{hPa}$, GRO has slightly larger RMSEs than CON at all times, except at $72 \mathrm{~h}$. As for DWS, the RMSEs are larger than those of $\mathrm{CON}$ at $850 \mathrm{hPa}$, but they become smaller at 500 and $300 \mathrm{hPa}$. With both the GPS RO and dropwindsonde data assimilated, ALL has even smaller RMSEs than either GRO or DWS at $500 \mathrm{hPa}$ for many time periods, but it still does not show any obvious improvement at 850 and $300 \mathrm{hPa}$.

The RMSEs of the east-west wind component ( $U$; Fig. 3d) increase over time from about 3 to $6 \mathrm{~m} / \mathrm{sec}$ at all levels. Error comparisons show that GRO does not perform well at the earlier time, but it improves after $24 \mathrm{~h}$ with smaller RMSEs. The RMSEs of DWS at the low level $(850 \mathrm{hPa})$ are mostly larger than those of $\mathrm{CON}$, but they are in general smaller at the mid and high levels (500 and $300 \mathrm{hPa}$ ). For several time periods, they are even the smallest among the four experiments. ALL performs very well in forecasting $U$ at many time periods. The RMSE distribution of the north-south wind component ( $V$; Fig. 3e) among different experiments is quite similar to that of $U$, except that the $V$ RMSEs are slightly larger.

From the above, it is clear that GPS RO data assimilation provides a positive impact on WRF simulations for many, though not all, meteorological fields; but the impact occurs mainly at the longer integration time. The reason is that in GRO there are only about 10-20 GPS RO observations inside domain 1 for each assimilation period, and it usually takes time for the influence to propagate into domain 2, where the verification is done. The dropwindsonde data also have a positive impact on the model simulations but primarily at the earlier forecast time. Because the observations were all taken in domain 2, their impact can be seen early in the forecast. When both the GPS RO and dropwindsonde data are assimilated in the model, the forecast error is further reduced.

\section{Mean error}

The mean errors (MEs) of CON show that the model underpredicts geopotential height, a problem which worsens as the forecast time increases (Fig. 4a). However, with the assimilation of the GPS data, the underestimation problem is reduced, except at the earlier time. The dropwindsonde data help to reduce the errors as well, although the differences are minimal. With both the GPS and dropwindsonde data assimilated, ALL overall predicts even larger geopotential height at 850 and $500 \mathrm{hPa}$, but it produces about the same $\mathrm{H}$ at $300 \mathrm{hPa}$ as GRO.
The temperature MEs (Fig. 4b) show a reverse pattern from the low to the high levels. They are positive at $850 \mathrm{hPa}$ near zero at $500 \mathrm{hPa}$ and negative at $300 \mathrm{hPa}$. This suggests that the model has a warm bias at the low level and a cold bias at the high level. As for crossexperiment comparisons, there is not much difference among the four experiments at 850 and $500 \mathrm{hPa}$. At $300 \mathrm{hPa}$, ALL appears to have the largest cold bias.

The RH MEs (Fig. 4c) reveal that the model underpredicts moisture at 850 and $300 \mathrm{hPa}$. The dry bias is worse at the high level (about -20\%) than at the low level (about $-10 \%$ ). At $500 \mathrm{hPa}$, the RH bias is very small. Compared with the relatively large RMSEs (15-30\%) shown in Fig. 3c, these small MEs suggest that the forecasts of RH at $500 \mathrm{hPa}$ are quite diverse. As for the relative performance among different experiments, the distribution is similar to that of RMSE.

The MEs of $U$ (Fig. 4d) are mostly positive, but they are in general small at $850 \mathrm{hPa}$. However, their RMSEs are not small $(3-6 \mathrm{~m} / \mathrm{s})$, which implies that the distribution of the errors is quite wide-ranging. At 500 and $300 \mathrm{hPa}$, the $U$ MEs show a positive bias. Another interesting feature is that the MEs of the four experiments exhibit a different pattern from that of the RMSEs. For example, GRO has the highest positive MEs, but its RMSEs are the lowest for most of the time periods. In other words, although the assimilation of the GPS data can reduce the RMSEs, it results in an increase in positive bias. This suggests that the occurrences of underprediction of $U$ are reduced, and that those of overprediction do not change much through the use of the GPS data. The $V$-component winds (Fig. 4e) show a similar pattern among different experiments to that of $U$, but the MEs are mostly negative at 500 and $300 \mathrm{hPa}$.

\section{Skill score}

Figure 5 shows the RMSE-based skill score (SS) of GRO against CON. Basically, the SSs more clearly demonstrate the improvement or worsening of the particular experiment over CON. At $300 \mathrm{hPa}$ (Fig. 5a), GRO shows positive SSs for geopotential height at all time periods, and the SS is the largest $(\sim 9 \%)$ at $24 \mathrm{~h}$. The other variables do not see significant improvement as for geopotential height, but they still exhibit a trend of increasing SS at the longer integration time. At $72 \mathrm{~h}$, the SSs are positive for all variables.

At 500 and $850 \mathrm{hPa}$ (Fig. 5b, c) GRO still shows, for almost all the variables, a tendency to improve forecast accuracy at the longer time. Geopotential height consistently has the largest SSs after $48 \mathrm{~h}$ of integration at these two levels. Combining the result at $300 \mathrm{hPa}$, it is clear that the GPS data provide useful information for height fields such that the forecast of geopotential height can be greatly 

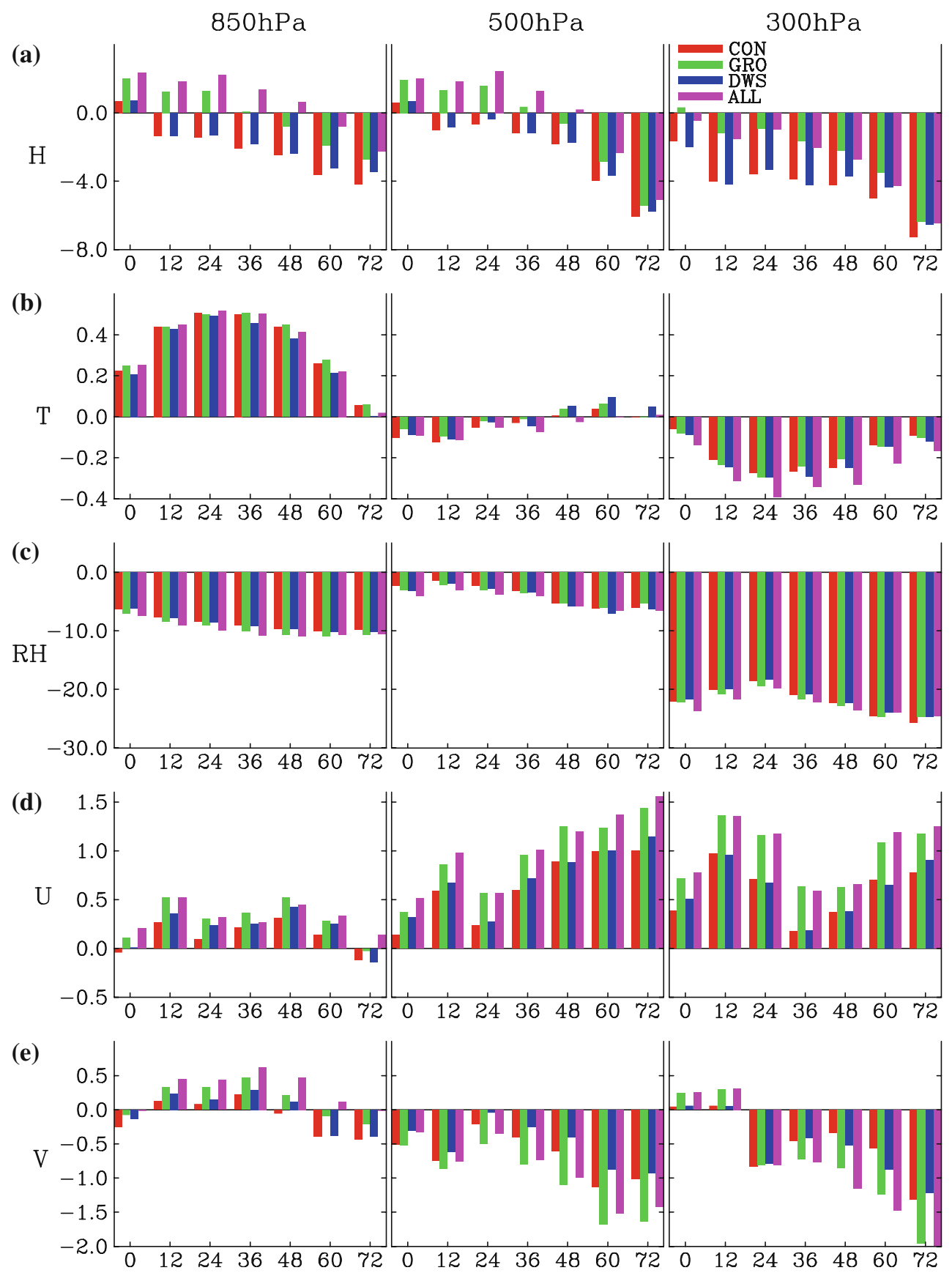

Fig. 4 Mean error (ME). See Fig. 3 for additional explanations

improved, especially after longer integration. The 500-hPa temperature forecasts of GRO also improve over CON, but the SSs are relatively small $(<4 \%)$. At $850 \mathrm{hPa}$, their SSs are close to zero. Relative humidity has positive SSs at $500 \mathrm{hPa}$, but negative SSs at $850 \mathrm{hPa}$. There are several possible reasons for this. First, the moisture analysis contains considerable uncertainties, and does not serve as a good source of verification for the prediction. Second, there is a negative refractivity bias in the GPS RO soundings
(Rocken et al. 1997), which affects the accuracy of moisture analysis. Third, over regions with significant moisture variability, such as near a Mei-yu front, a more sophisticated nonlocal observation operator should be used (e.g., Sokolovskiy et al. 2006) for the assimilation of GPS RO data.

Compared with GRO, DWS has lower SSs $(<5 \%)$ and it does not show a trend of improvement over time (Fig. 6). Instead, the SSs are in general higher at the earlier time and 
(a)

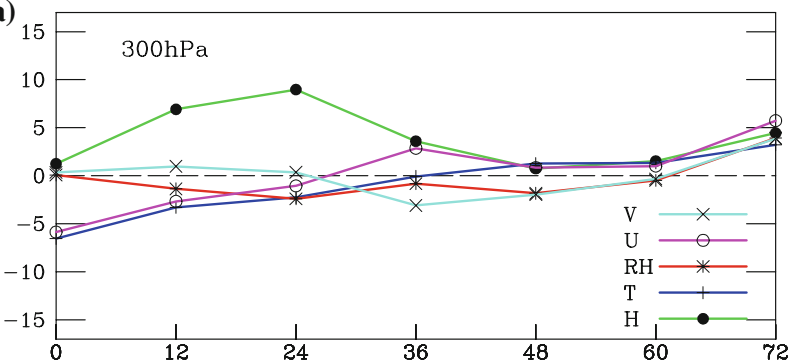

(b)

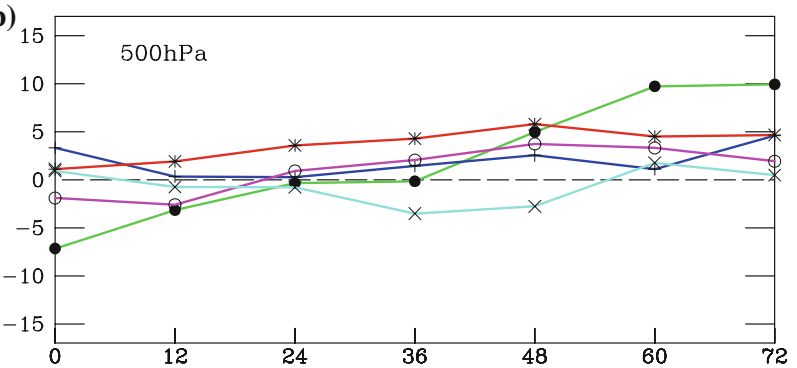

(c)

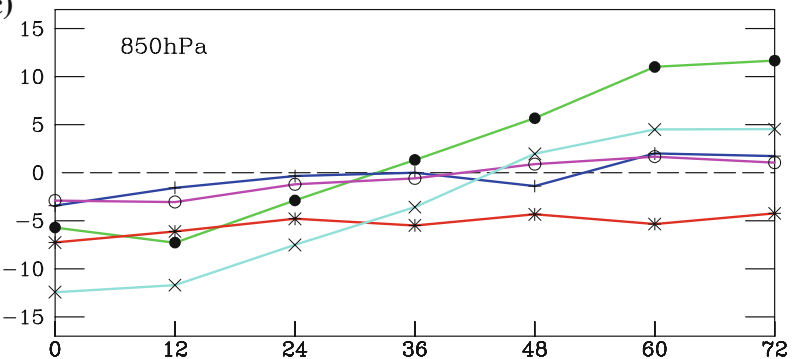

Fig. 5 Skill score (\%) for GRO against CON. The pressure levels are at a 300, b 500, and c $850 \mathrm{hPa}$. The abscissa denotes time elapsed in the simulation (h). Color curves in green, blue, red, magenta, and cyan represent results for $H, T, \mathrm{RH}, U$, and $V$, respectively

they decrease as the integration time increases. The assimilation of dropwindsonde data helps to improve the simulation for most of the variables at 300 and $500 \mathrm{hPa}$, but it barely shows forecast improvement at $850 \mathrm{hPa}$.

With both the GPS RO and the dropwindsonde data assimilated in the model, ALL (Fig. 7) shows even higher SSs than either GRO or DWS. The most notable is the forecast of geopotential height. Its SSs are relatively high; for example, they are up to $15 \%$ at $850 \mathrm{hPa}$ in the 60- and 72-h forecasts. The tendency of SSs for each variable is very similar to that of GRO, except with some minor differences. This is because the dropwindsonde data are available only in six out of the 22 runs. Their overall impact is relatively small compared with that of the GPS data.

\section{Statistical analysis}

In order to examine statistically the impact of the GPS RO and dropwindsonde data, we have performed a statistical analysis by counting the number of times positive/negative (a)

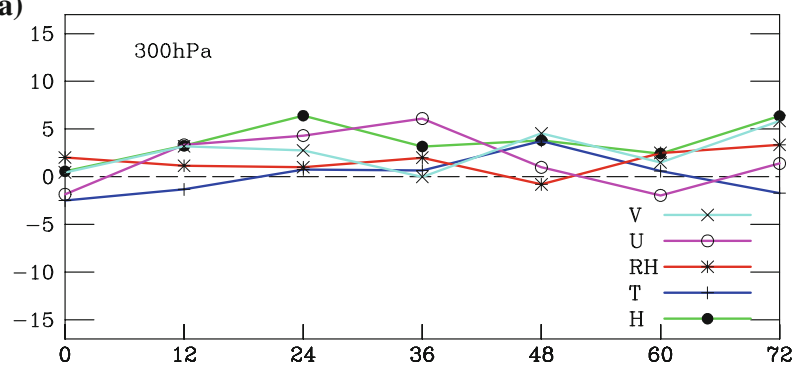

(b)

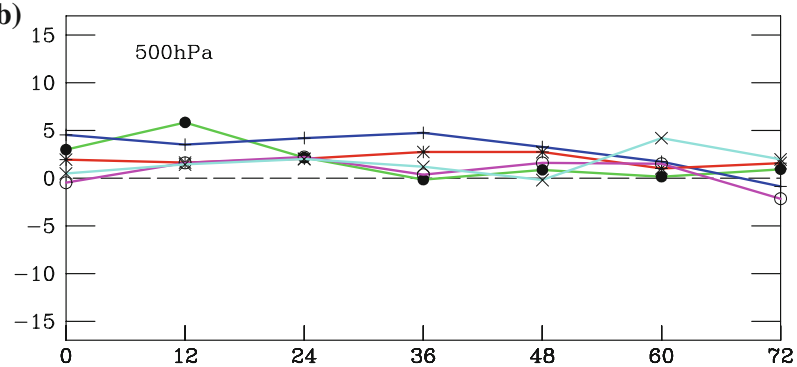

(c)

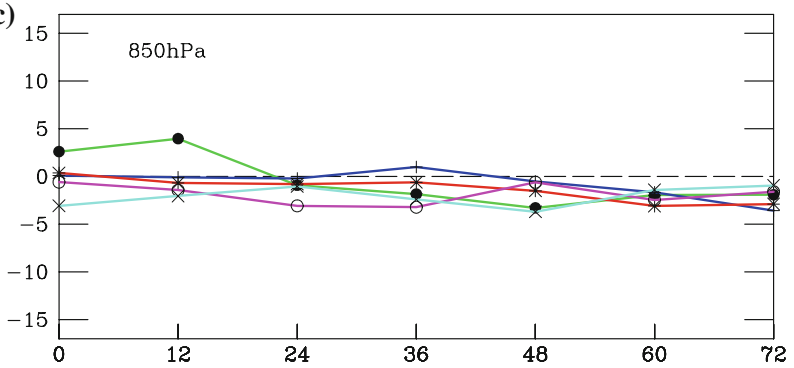

Fig. 6 Skill score (\%) for DWS against CON. For additional explanations see Fig. 5

RMSE differences (or SSs) occurred between CON and a particular experiment. The differences were computed for all HTRUV fields at five levels $(1,000,850,700,500$, and $300 \mathrm{hPa})$, and at six forecast times $(12,24,36,48,60$, and $72 \mathrm{~h}$ ). A positive (negative) value indicates that a particular experiment performs better (worse) than CON. In addition, we used the resampling technique of Wilks (1995) to test whether the difference exceeded a significance level of $75 \%$. Table 3 shows that the GPS RO data produce the biggest impact on the forecast of geopotential height among the five variables. Although temperature, relative humidity, and $U$-component wind exhibit many positive differences, they are typically not as significant as geopotential height. The dropwindsonde data (DWS) bring a nearly equal effect on the forecast of each field. With both datasets assimilated (ALL), the number of occurrences of positive impact and that of high significance both increase.

We further stratified the numbers according to the vertical levels and the forecast time periods. From Table 4, it is evident that the GPS RO data help the forecast the most at $500 \mathrm{hPa}$, and the least at $850 \mathrm{hPa}$. The dropwindsonde data also produce a very significant impact at high levels such as 500 and $300 \mathrm{hPa}$, but worsen the forecast at 
(a)

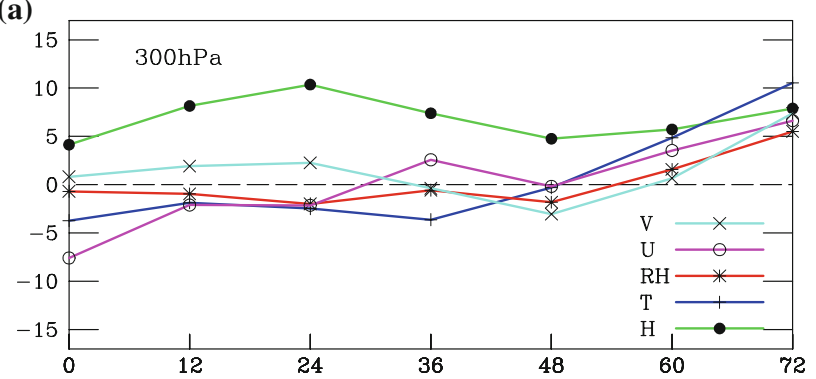

(b)

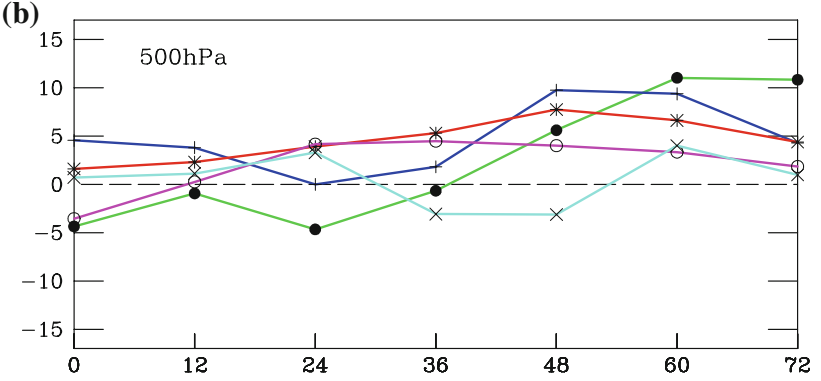

(c)

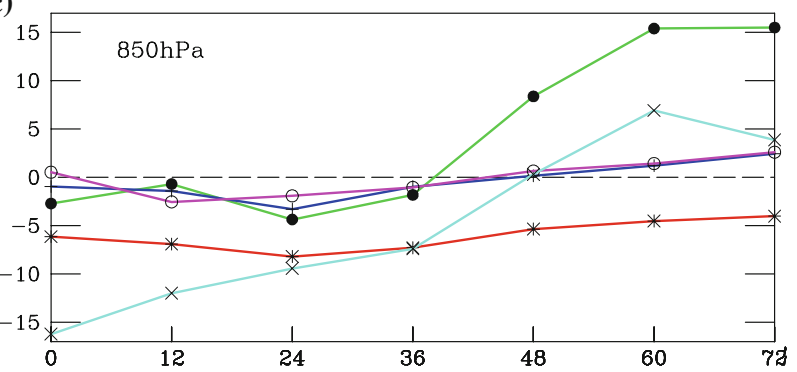

Fig. 7 Skill score (\%) for ALL against CON. For additional explanations see Fig. 5

$850 \mathrm{hPa}$. As stratified by the six forecast times, the numbers in Table 5 clearly indicate that the positive impact of the GPS RO data increases over time, while that of the dropwindsonde data decreases as the forecast time increases.

\section{Verification of rain}

In addition to the aforementioned meteorological fields, we also performed verification of $12-\mathrm{h}$ precipitation forecasts against the observations from 390 rain gauges in Taiwan. The equitable threat score (ETS) and bias are computed for verification. They are defined as follows:

$\mathrm{ETS}=\frac{H-R}{F+O-H-R}$

Bias $=\frac{F}{O}$

where $H$ is the number of hits, and $F$ and $O$ are the numbers of samples in which the precipitation amounts are greater than the specified rain threshold in forecast and observation, respectively. The random forecast is $R=F O / N$, where $N$ is the number of points being verified. Eight rain thresholds are used in this study, including $0.3,2.5,5,10$, 15 25, 35, and $50 \mathrm{~mm}$ (see Chien and Jou 2004 for more details).

Figure 8 presents the ETS and bias of the 12-h rainfall forecasts of the four experiments. For brevity, only the results between 12 and $60 \mathrm{~h}$ in the simulation are shown. The ETS and bias of the rainfall forecast at $0-12$ and 60-72 $\mathrm{h}$ are not discussed here because the former is still in model spin-up stage, and the latter is out of the time window of model peak performance for rainfall prediction from a mesoscale model. At 12-24 h (Fig. 8a), the ETSs of CON (\#1 curve) are slightly below 0.3 for rain thresholds smaller than $35 \mathrm{~mm}$, and drop to below 0.2 at the $50-\mathrm{mm}$ threshold. The corresponding biases are very good, around 1 for all thresholds. Compared with $\mathrm{CON}$, there is nearly no improvement in terms of ETS for either GRO (\#2 curve) or DWS (\#3 curve). DWS even produces much lower ETSs at thresholds between 10 and $35 \mathrm{~mm}$. ALL (\#4 curve) is the worst among all the experiments at small thresholds, but it becomes better at large thresholds.

At 24-36 h (Fig. 8b), the ETSs show that both GRO and DWS predict better rainfall than $\mathrm{CON}$ at small thresholds ( $\leq 5 \mathrm{~mm}$ ), but do worse than $\mathrm{CON}$ at large thresholds ( $\geq 35 \mathrm{~mm}$ ). In a similar manner, ALL has the highest ETSs at those small thresholds and the lowest ETSs at those large thresholds. Biases of all the experiments are still very good for this forecast time period.

The ETSs of the rainfall forecast at 36-48 h (Fig. 8c) indicate that GRO produces the highest ETS at almost all

Table 3 RMSE differences of the HTRUV fields between CON and each of the three experiments (GRO, DWS, and ALL)

\begin{tabular}{llllll}
\hline Exps. & $H$ & $T$ & RH & $U$ & $V$ \\
\hline CON-GRO & $17(11) / 13(6)$ & $22(3) / 8(0)$ & $18(6) / 12(6)$ & $18(2) / 12(0)$ & $12(2) / 18(6)$ \\
CON-DWS & $15(3) / 15(0)$ & $17(3) / 13(0)$ & $17(3) / 13(2)$ & $14(8) / 16(6)$ & $21(7) / 9(0)$ \\
CON-ALL & $17(14) / 13(3)$ & $15(6) / 15(1)$ & $14(4) / 16(0)$ \\
\hline
\end{tabular}

The differences are computed at five levels $(1,000,850,700,500$, and $300 \mathrm{hPa})$ and at six forecast times $(12,24,36,48,60$, and 72 h). The number of times positive/negative values (separated by a slash) occurred out of 30 verification scores is shown for the five fields. Positive values mean positive impact of the particular experiment, and vice versa. The numbers in parentheses denote the number of times the difference exceeded a statistical significance level of $75 \%$ 
Table 4 RMSE differences for the five vertical levels between CON and each of the three experiments (GRO, DWS, and ALL)

\begin{tabular}{llllll}
\hline Exps. & $1,000 \mathrm{hPa}$ & $850 \mathrm{hPa}$ & $700 \mathrm{hPa}$ & $500 \mathrm{hPa}$ & $300 \mathrm{hPa}$ \\
\hline CON-GRO & $17(3) / 13(5)$ & $13(4) / 17(9)$ & $18(4) / 12(3)$ & $22(9) / 8(1)$ & $17(5) / 13(0)$ \\
CON-DWS & $13(0) / 17(0)$ & $2(0) / 28(1)$ & $11(1) / 19(0)$ & $26(5) / 4(0)$ & $25(11) / 5(0)$ \\
CON-ALL & $15(3) / 15(6)$ & $12(4) / 18(10)$ & $14(8) / 16(2)$ & $24(16) / 6(1)$ & $17(9) / 13(0)$ \\
\hline
\end{tabular}

For additional explanations see Table 3

Table 5 RMSE differences for the six forecast times between CON and each of the three experiments (GRO, DWS, and ALL)

\begin{tabular}{lllllll}
\hline Exps. & $12 \mathrm{~h}$ & $24 \mathrm{~h}$ & $36 \mathrm{~h}$ & $48 \mathrm{~h}$ & $60 \mathrm{~h}$ & $72 \mathrm{~h}$ \\
\hline CON-GRO & $7(2) / 18(6)$ & $10(3) / 15(4)$ & $12(2) / 13(3)$ & $16(4) / 9(2)$ & $20(6) / 5(2)$ & $22(8) / 3(1)$ \\
CON-DWS & $16(5) / 9(0)$ & $15(4) / 10(0)$ & $11(3) / 14(0)$ & $13(1) / 12(0)$ & $12(2) / 13(1)$ & $10(2) / 15(0)$ \\
CON-ALL & $10(2) / 15(4)$ & $9(6) / 16(6)$ & $8(4) / 17(4)$ & $14(7) / 11(2)$ & $20(9) / 5(2)$ & $21(12) / 4(1)$ \\
\hline
\end{tabular}

For additional explanations see Table 3

the rainfall thresholds. This is because the model starts to overpredict rainfall (with large biases) during this time period, while GRO appears to have a less severe overprediction problem. On the contrary, DWS has the highest biases, and its ETSs are the worst among the four experiments at thresholds larger than $10 \mathrm{~mm}$. The ETSs of ALL are nearly the same as CON, except at small thresholds, where the ETSs of ALL are slightly higher.

At 48-60 h (Fig. 8d), GRO still has the highest ETSs, except at large thresholds where the ETSs are low and the biases are high. The biases of DWS are not too bad (close to 1) and its ETSs become better, but ALL overall does not perform well during this time period.

\section{Summary and conclusions}

This paper presents an impact study of the GPS radio occultation and dropwindsonde data on WRF forecasts during a 11-day period of the 2007 Mei-yu season. Many mesoscale convective systems developed along the Mei-yu front and produced heavy rainfall over Taiwan during this time period. Data assimilation with 12-h update cycling was performed using the WRF-Var system. The verification was performed for five basic meteorological fields (geopotential height, temperature, relative humidity, and $U$ - and $V$-component winds) and rain on the $15-\mathrm{km}$ grid.

The verification results show that the forecast of geopotential height has an underprediction problem, with RMSEs increasing over time from about 5 to $20 \mathrm{~m}$. Temperature predictions show a warm bias at the low level and a cold bias at the high level. The error range is about $1^{\circ} \mathrm{C}$ at $850 \mathrm{hPa}$ and becomes smaller at higher levels. The model overall tends to underpredict relative humidity, with a larger dry bias $(\sim 20 \%)$ at $300 \mathrm{hPa}$, a smaller bias $(\sim 10 \%)$ at $850 \mathrm{hPa}$, and nearly no bias at $500 \mathrm{hPa}$. As for winds, the $U$-component wind has a positive bias and the $V$-component wind in general has a negative bias. Their RMSEs range from 3 to $6 \mathrm{~m} / \mathrm{s}$.

The assimilation of the GPS RO data can help to improve the WRF forecast at the longer forecast time (e.g., $>36 \mathrm{~h}$ ). The forecast of geopotential height, among the five meteorological variables, reflects most notably the impact of the GPS data. All the variables at all levels more or less show a positive impact, save for relative humidity, which has negative SSs at $850 \mathrm{hPa}$. The impact of assimilating the dropwindsonde data is, in general, positive at high levels like 300 and $500 \mathrm{hPa}$, and it decreases over time. Because there are usually very few GPS RO observations located in the fine domain, it takes time for the influence to propagate from the coarse domain into the region where the verification is done. In other words, the large-scale simulation is first improved due to the GPS RO observations, and the change can then have a positive impact on the mesoscale at a later time. The dropwindsonde observations, however, are taken inside the fine domain such that their impact can be detected early in the simulation. This reflects the fact that GPS RO is primarily a large-scale observation (both in terms of its measurement characteristics and data distribution), while the dropsonde is primarily a mesoscale observation. With both the GPS RO and dropwindsonde data assimilated, the model improves even further. It is also found that a 6-h update cycling strategy can further improve the forecast by assimilating more GPS RO data into the model, but the difference is not very significant.

The GPS and dropwindsonde data start to improve the rainfall forecast only after $24 \mathrm{~h}$. At 36-60 h, the GPS RO data significantly improve the rainfall prediction because the overprediction problem of the model is reduced. Compared with the verification of the five meteorological 
Fig. 8 The ETS (left) and bias (right) of 12-h precipitation forecasts from CON (black, \#1), GRO (red, \#2), DWS (blue, \#3), and ALL (green, \#4). The absciss $a$ is the rainfall thresholds $(\mathrm{mm})$. Time periods of the 12-h rainfall verified include a $12-24 \mathrm{~h}$, b $24-36 \mathrm{~h}$, c $36-48 \mathrm{~h}$, and d $48-60 \mathrm{~h}$

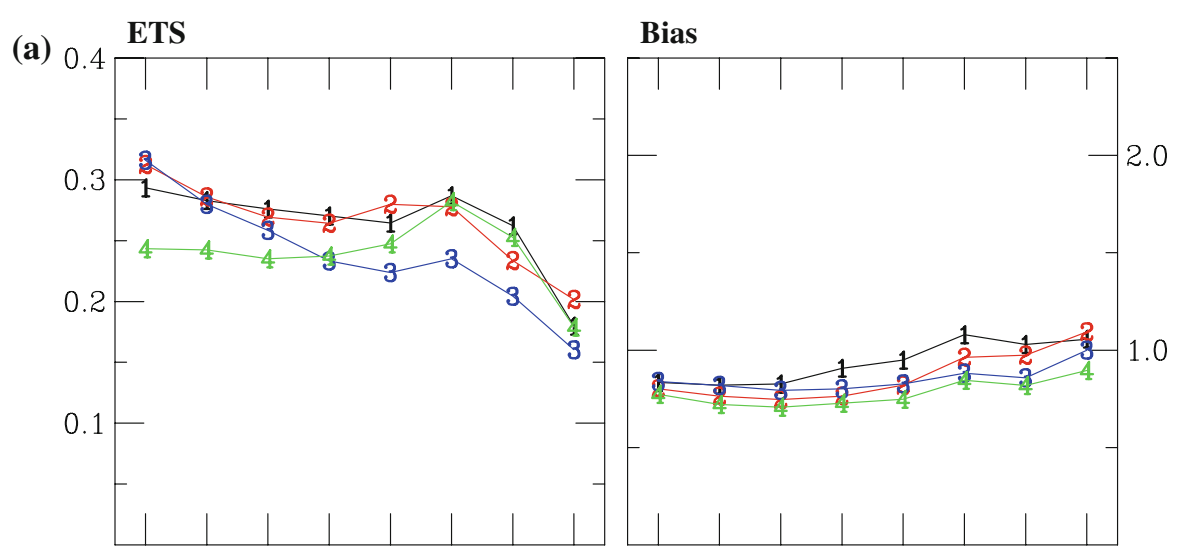

(b) 0.4

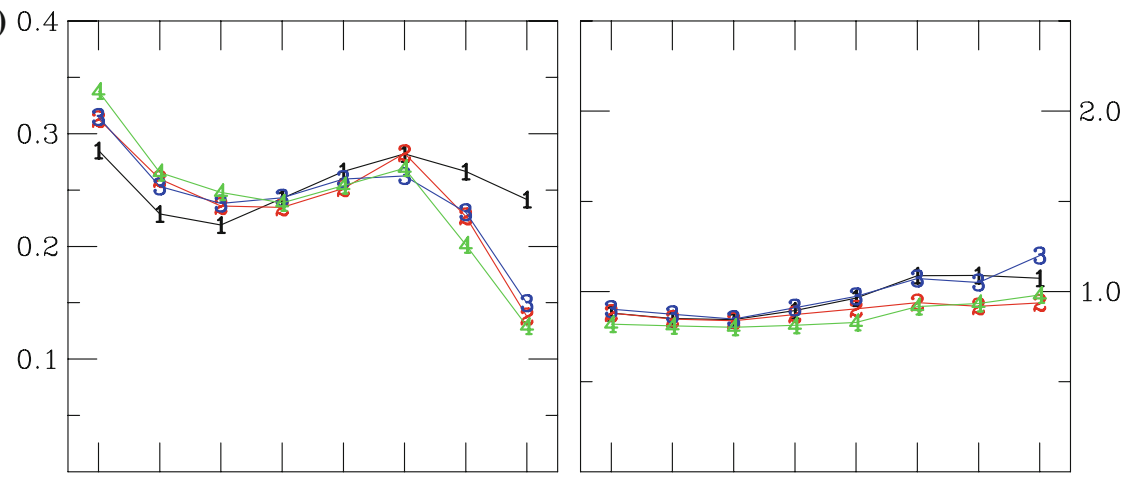

(c) 0.4

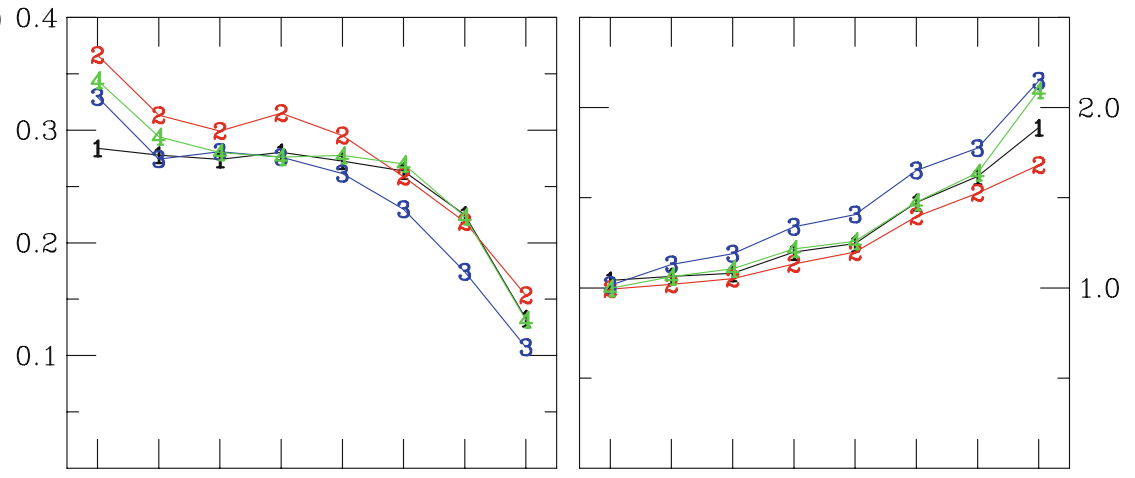

(d) 0

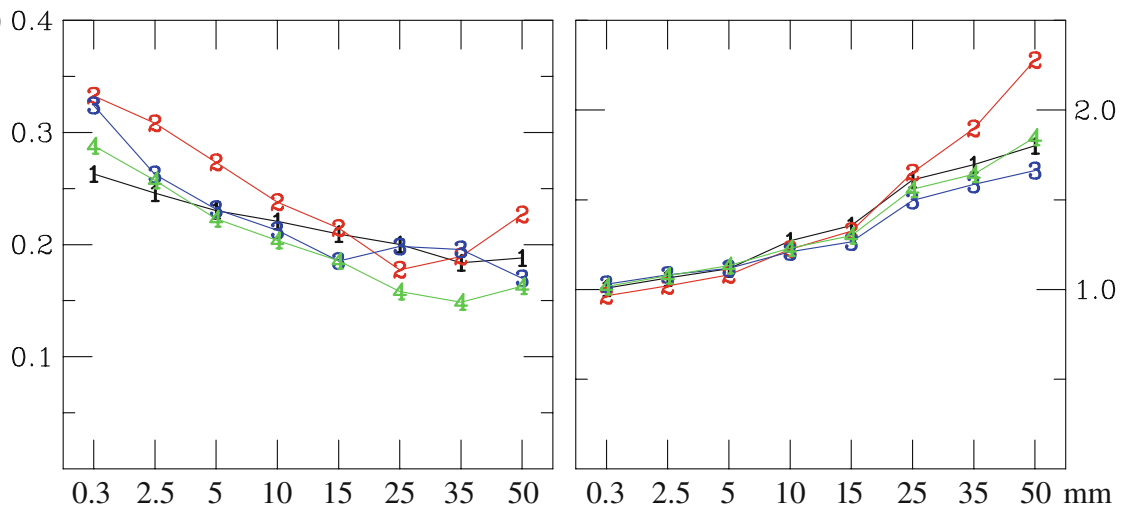

fields, this suggests that when the model better simulates basic fields with the GPS RO data the rainfall is better predicted because the dynamics and physics processes are better reproduced. An exception to this, however, is the simulation of low-level (850 hPa) moisture, because with the GPS RO data assimilation, the moisture simulation is not improved. Since low-level moisture is very important in determining the accuracy of precipitation, these 
inconsistent results lead us toward a possible explanation that the moisture analysis we have used does not serve as a good source of verification for the prediction. This is often the case, as moisture analysis usually contains considerable uncertainties at low levels. Another possibility is that there is a negative refractivity bias in the GPS RO soundings, which affects the accuracy of moisture analysis. In addition, over regions with significant moisture variability, such as near a Mei-yu front, a more sophisticated nonlocal observation operator or direct assimilation of bending angle could be considered. The dropwindsonde data also provide a positive impact on rainfall forecasts, but it is not as significant as that of the GPS RO data. It should be noted, however, that the above results are based on the current data availability of dropwindsonde observations in the field program. If dropwindsonde data were available at more frequent model initial times, their impact would probably be greater. However, since such observations are usually distributed in a limited area, the impact should be minimal compared to that of the GPS RO data when a large-scale weather system is dominant.

Acknowledgments This research was supported by the National Space Organization (NSPO) of Taiwan under Grand 96-NSPO(B)-SPFA07-03(D) and the National Science Council of Taiwan (Grants NSC 95-2625-Z-003-001 and NSC 95-2111-M-003-001-AP2). We thank the Central Weather Bureau for providing numerical and observational data, Sheng-Feng Lin for performing the numerical experiments, Pao-Liang Chang for providing the radar image, YongRun Guo for helping us with WRF-Var, and Sara Frank Bristow for proofreading the manuscript.

Open Access This article is distributed under the terms of the Creative Commons Attribution Noncommercial License which permits any noncommercial use, distribution, and reproduction in any medium, provided the original author(s) and source are credited.

\section{References}

Aberson SD, Franklin JL (1999) Impact on hurricane track and intensity forecasts of GPS dropwindsonde observations from the first-season flights of the NOAA Gulfstream-IV jet aircraft. Bull Am Meteor Soc 80:421-427

Anthes RA, Rocken C, Kuo YH (2000) Applications of COSMIC to meteorology and climate. Terr Atmos Oceanic Sci 11:115156

Anthes RA et al (2008) The COSMIC/FORMOSAT-3 mission: early results. Bull Am Meteor Soc 89:313-333

Burpee RW, Aberson SD, Franklin JL, Lord SJ, Tuleya RE (1996) The impact of omega dropwindsondes on operational hurricane track forecast models. Bull Am Meteor Soc 77:925-933

Chen GTJ, Wang CC, Lin LF (2006) A diagnostic study of a retreating Mei-yu front and the accompanying low-level jet formation and intensification. Mon Wea Rev 134:874-896
Chien FC, Jou BJD (2004) MM5 ensemble mean precipitation forecasts in the Taiwan area for three Mei-yu seasons. Wea Forecast 19:735-750

Chien FC, Liu YC, Jou BJD (2006) MM5 ensemble mean forecasts in the Taiwan area for the 2003 Mei-yu season. Wea Forecast 21:1006-1023

Chien FC, Liu YC, Lee CS (2008) Heavy rainfall and southwesterly flow after the leaving of Typhoon Mindulle (2004) from Taiwan. J Meteor Soc Jpn 86:17-41

Cucurull L, Kuo YH, Barker D, Rizvi SRH (2006) Assessing the impact of simulated COSMIC GPS radio occultation data on weather analysis over the Antarctic: a case study. Mon Wea Rev 134:3283-3296

Cucurull L, Derber JC, Treadon R, Purser RJ (2007) Assimilation of global positioning system radio occultation observations into NCEP's Global Data Assimilation System. Mon Wea Rev 135:3174-3193

Cucurull L, Derber JC, Treadon R, Purser RJ (2008) Preliminary impact studies using global positioning system radio occultation profiles at NCEP. Mon Wea Rev 136:1865-1877

Healy S, Thepaut JN (2006) Assimilation experiments with CHAMP GPS radio occultation measurements. Q J R Meteor Soc 132:605-623

Kuo YH, Wee TK, Sokolovskiy S, Rocken C, Schreiner W, Hunt D, Anthes RA (2004) Inversion and error estimation of GPS radio occultation data. J Meteor Soc Jpn 82:507-531

Kuo YH, Liu H, Guo YR, Terng CT, Lin YT (2008) Impact of FORMOSAT-3/COSMIC data on typhoon and Mei-yu prediction. In: Liou KN, Chou MD (eds) 2008, recent progress in atmospheric sciences: applications to the Asia-Pacific region. World Scientific Publishing, Singapore, 496 p

Kursinski ER, Hajj GA, Hardy KR, Schofield JT, Linfield R (1997) Observing Earth's atmosphere with radio occultation measurements. J Geophys Res 102:23429-23465

Lin YL, Chiao S, Wang TA, Kaplan ML, Weglarz RP (2001) Some common ingredients for heavy orographic rainfall. Wea Forecast 16:633-660

Liu H, Zou X, Shao H, Anthes R, Chang J, Tseng JH, Wang B (2001) Impact of 837 GPS/MET bending angle profiles on assimilation and forecasts for the period June 20-30, 1995. J Geophys Res 106:31771-31786

Rocken CR et al (1997) Analysis and validation of GPS/MET data in the neutral atmosphere. J Geophys Res 102:2984929866

Skamarock WC, Klemp JB, Dudhia J, Gill DO, Baker DM, Wang W, Powers JG (2005) A description of the advanced research WRF version 2. NCAR Tech. Note NCAR/TN-468+STR, $88 \mathrm{p}$

Sokolovskiy S, Rocken C, Hunt D, Schreiner W, Johnson J, Masters D, Esterhuizen S (2006) GPS profiling of the lower troposphere from space: inversion and demodulation of the open-loop radio occultation signals. Geophys Res Lett 33:L14816. doi:10.1029/ 2006GL026112

Wilks DS (1995) Statistical methods in the atmospheric sciences. Academic Press, $467 \mathrm{p}$

Wu CC et al (2005) Dropwindsonde observations for typhoon surveillance near the Taiwan region (DOTSTAR): an overview. Bull Am Meteor Soc 86:787-790

Wu CC et al (2007) The impact of dropwindsonde data on typhoon track forecasts in DOTSTAR. Wea Forecast 22:1157-1176

Zou X, Liu H, Anthes R, Shao H, Chang J, Zhu YJ (2004) Impact of CHAMP radio occultation observations on global analyses and forecasts in the absence of AMSU radiance data. J Meteor Soc Jpn 82:533-549 


\section{Author Biographies}

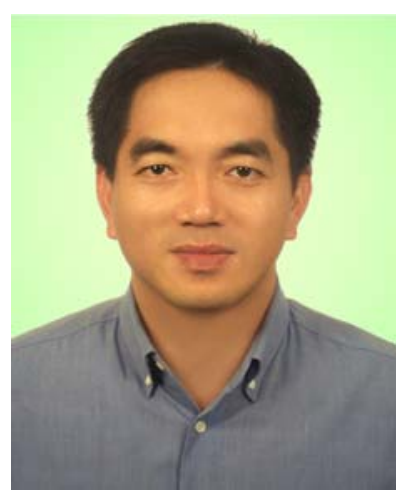

Fang-Ching Chien received his B.Sc. and M.Sc. from the Department of Atmospheric Sciences, National Taiwan University, Taiwan in 1985 and 1987, respectively. After 2 years of military service and 2 years of working in Civil Aeronautics Administration and National Taiwan University, he continued his graduate study and received his Ph.D. degree in the Department of Atmospheric Sciences, University of Washington, US in 1997. He is currently a professor in the Department of Earth Sciences, National Taiwan Normal University, Taiwan. His research interests focus on numerical weather prediction, data assimilation, and mesoscale meteorology.

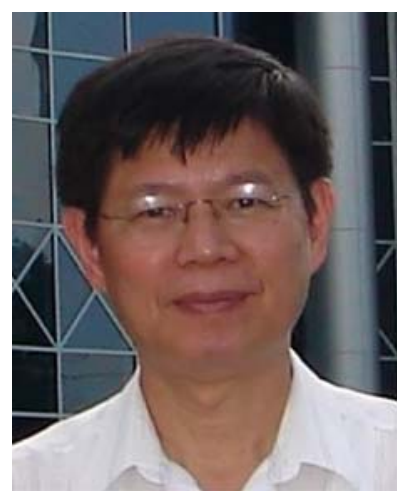

Ying-Hwa Kuo is the Director of the UCAR COSMIC Project and the Head of Mesoscale Prediction Group/MMM Division at NCAR. Dr. Kuo received his $\mathrm{Ph} . \mathrm{D}$. in Meteorology from the Pennsylvania State University in 1983. He is a recognized leader in the field of mesoscale numerical modeling, meteorological data assimilation, and the applications of GPS radio occultation observation to weather prediction. He has served as the NCAR advisor for over 20 Ph.D. students since 1988. Dr. Kuo has published over 120 journal papers, and numerous conference articles and reports. His scientific interest includes: mesoscale modeling, explosive marine cyclogenesis, mesoscale convective systems, heavy rainfall prediction, data assimilation, GPS/MET research, and model initialization. 